\section{CASE REPORT}

doi: 10.5455/medarh.2015.69.423-424

Med Arh. 2015 Dec; 69(6): 424-425 Received: August 25th 2015 | Accepted: October 25th 2015

(c) 2015 Hajdin Citaku, Lulzim Kamberi, Daut Gorani, Dardan Kocinaj, Xhevdet Krasniqii

This is an Open Access article distributed under the terms of the Creative Commons Attribution Non-Commercial License (http://creativecommons.org/licenses/ by-nc/4.0/) which permits unrestricted non-commercial use, distribution, and reproduction in any medium, provided the original work is properly cited.

\title{
Anomalous Origin of Left Circumflex Artery
}

\author{
Hajdin Çitaku, Lulzim Kamberi, Daut Gorani, Dardan Koçinaj, \\ Xhevdet Krasniqi
}

Clinic for Cardiology, University Clinical Centre of Kosova, Prishtina, Republic of Kosovo

Corresponding author: Hajdin Citaku, MD. E-mail: dinicitaku@hotmail.com

\begin{abstract}
Introduction: The coronary anatomic variation of the left circumflex artery (LCx) is considered as the most common anatomic variation with a separate ostium from the right sinus, and very unusual variation as a proximal branch of right coronary artery (RCA). Case report: We report two cases, the first case is a 64-year-old man with chest pain and with history of hypertension, obesity, dyslipidemia and current smoker, and the second case is a 67-year-old who presented to the emergency department with chest pain and with a past medical history of arterial hypertension and type 2 diabetes mellitus. In the coronarography of the first case is detected an ectopic left circumflex coronary artery from the right coronary sinus with stenotic changes in RCA and LCx. The second case in the coronary angiography revealed an ectopic left circumflex coronary artery from the proximal part of the right coronary artery with stenotic changes in LAD, RCA and LCx. Based on guidelines for revascularization our patients successfully underwent treatment procedures. We present two cases that because of the atherosclerotic coronary artery disease leads to the need of coronarography find out the presence of coronary artery anomalies. Conclusion: During the coronarography we should think about coronary artery anomaly or missing artery knowing that type of these anomalies, considering that may be a contributing factor in the development of the atherosclerosis determines the method of the treatment.
\end{abstract}

Key words: left circumflex artery, anomalous origin.

\section{INTRODUCTION}

Congenital coronary anomalies are generally reported to be about $1 \%$ (ranging from 0.2 to $1.3 \%$ ) based on adult angiographic series and $0.3 \%$ based on autopsy series $(1,2)$.

The most common coronary anatomic variation is the anomalous left circumflex artery (ALCx) that can be found in approximately 0.37 to $0.7 \%$ of all patients $(3,4)$. This anomaly arises from a separate ostium within the right sinus, or a very unusual as a proximal branch of the right coronary artery (RCA). In adult patients relationship of the arterial course to the aorta and pulmonary arteries considering vulnerability to atherosclerosis determined prognosis of coronary artery anomalies that are associated with life-threatening conditions including congestive heart failure, arrhythmia, myocardial infarction, syncope and sudden death (4-7). In this paper, we presented two cases of coronary anatomic variations of the left circumflex artery from the right sinus of Valsalva, and the left circumflex artery as a proximal branch of the right coronary artery (RCA).

\section{CASES REPORTS}

The first case is 64-year-old man hospitalized to our clinic due to of chest pain. Also, patient was a smoker and had a history of arterial hypertension, obesity, and dyslipidemia. The physical findings characterized with blood pressure, 125/80 mmHg; pulse rate, 80 beats/min; respiratory rate, 20 breaths/min; and body temperature, $36.8^{\circ} \mathrm{C}$. Biochemical parameters were: serum creatinine kinase level of $520 \mathrm{IU} / \mathrm{L}$, creatine kinase-myocardial band level of 6.5 $\mathrm{ng} / \mathrm{mL}$ and troponin-I level of 0.1 $\mathrm{ng} / \mathrm{mL}$. Electrocardiography characterized with deep Q wave in inferior leads and in V4-V6 with biphasic T in D2, D3, aVF, and V3-V6. In transthoracic echocardiography (TTE) is presented regional wall motion abnormalities in the entire severely hypokinetic inferoposterior wall. 


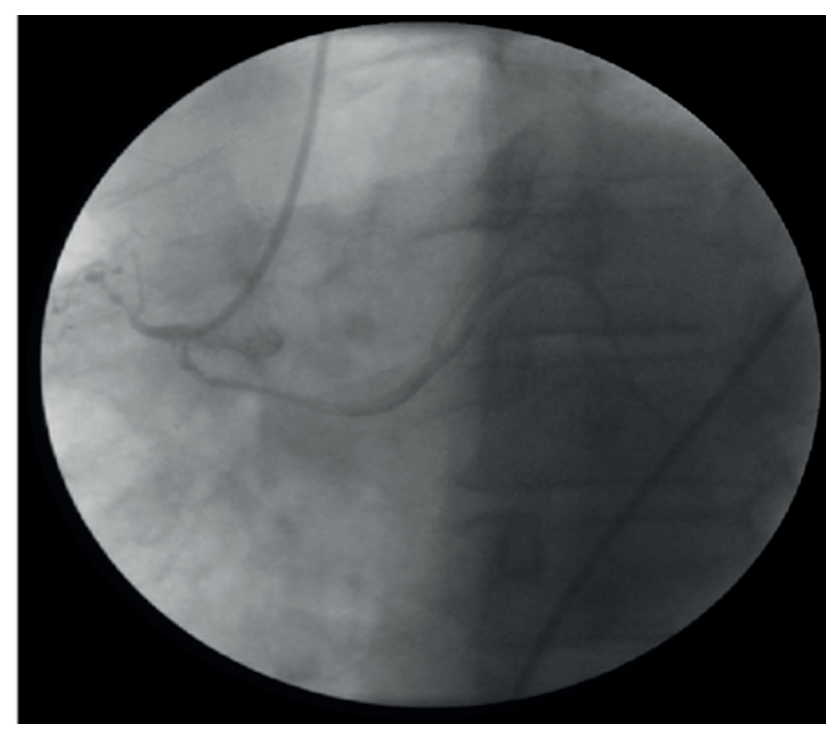

Figrue 1. Revealed LCx arising from right coronary sinus

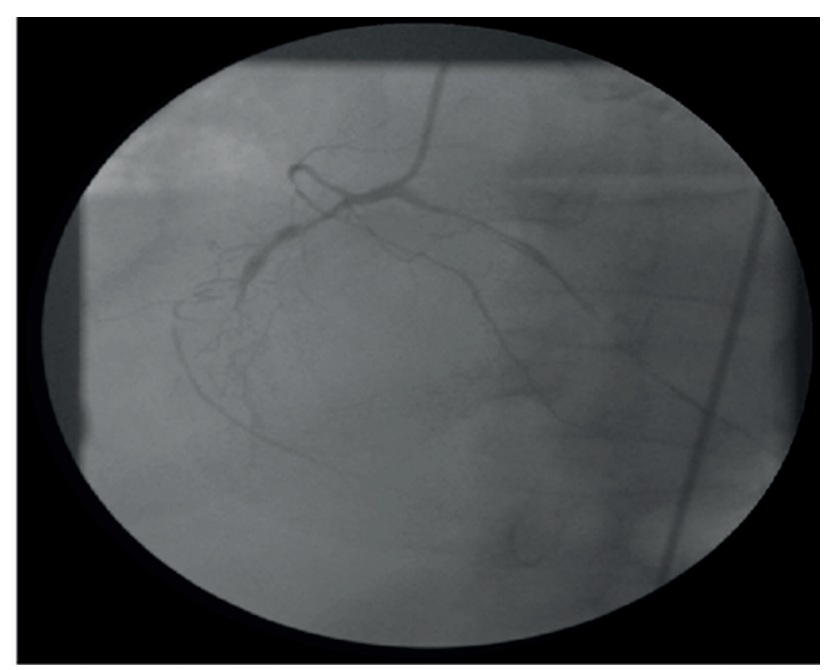

Figrue 2. Revealed a LCx as a proximal branch of RCA

The patient underwent coronary angiography that revealed the $\mathrm{LCx}$ arising from the right coronary sinus (Figure 1). The mildly stenosed LCx coexists with a stenosed RCA. The second case is 67-year-old man presented to the emergency department with chest pain that had developed two hours previously. The patient had a history of arterial hypertension for 10 years, diabetes mellitus for 5 years, and chronically hemodialyzed for 7 years. The vital signs were as follows: blood pressure, 130/80 mmHg; pulse rate, 90 beats/min; respiratory rate, 22 breaths $/ \mathrm{min}$; and body temperature, $36.8^{\circ} \mathrm{C}$. The laboratory findings showed a serum creatinine kinase level of $473 \mathrm{IU} / \mathrm{L}$, creatine kinase-myocardial band level of $6.4 \mathrm{ng} / \mathrm{mL}$ and troponin-I level of $0.15 \mathrm{ng} / \mathrm{mL}$. Electrocardiography demonstrated ST segment depression of 1-2 mm in leads V4-V6, and inverted $\mathrm{T}$ wave in D2, D3, aVF. The transthoracic echocardiography (TTE) revealed severely hypokinetic medioapical segments of anterolateral wall, and hypokinetic basal segments of interventricular septum and inferior wall. The coronary angiography revealed a left circumflex artery (LCx) as a proximal branch of the right coronary artery (RCA) (Figure 2). The LAD contained an proximal lesion up to $80 \%$. The LCx and RCA are occluded in medial segment.

\section{DISCUSSION}

During the third week of fetal development can occur changes resulting in presentation of coronary artery anomalies with a prevalence ranges from $0.3 \%$ to $1.3 \%$ based on previously reported angiographic series $(2,8)$.

The sudden cardiac death in patients with coronary artery anomalies may result from contortion of the vessel's slit-like, tangential origin that during exercise leading to ischemia and resultant arrhythmia (9).

Also based on results of other authors the poor prognosis associated with anomalous coronary arteries originating from the RSV results from the severity of ischemia that is related to degree of coronary intussusception, level of intramural hypoplasia, and compression of the pulmonary trunk or aorta as a result of an increase in pressure in these vessels during exercise $(10,11,12)$.

Some authors have suggested that coronary segments with an anomalous course are vulnerable to atherosclerosis making that coronary artery anomalies which presented with STEMI to be a complex occurrence $(7,13)$.

\section{CONCLUSION}

The atherosclerotic coronary artery disease leads to the need of coronarography which can find out the presence of coronary artery anomalies. We should think about these anomalies during coronarography knowing that based on type of these anomalies and considering the vulnerability to atherosclerosis will be determined the method of the treatment.

\section{CONFLICT OF INTEREST: NONE DECLARED.}

\section{REFERENCES}

1. Zhang LJ, Yang GF, Huang W, et al. Incidence of anomalous origin of coronary artery in 1879 Chinese adults on dual-source CT angiography. Neth Heart J. 2010; 18: 466-470.

2. Yamanaka O, Hobbs RE. Coronary artery anomalies in 126,595 patients undergoing coronary arteriography. Cathet Cardiovasc Diagn. 1990; 21: 28-40.

3. Rozenman Y. Anomalous origin of the circumflex coronary artery from the right sinus of Valsalva as a cause of ischemia at old age. Clin Cardiol. 1993; 16: 900-901.

4. Yuksel S, Meric M, Soylu K. et al. The primary anomalies of coronary artery origin and course: A coronary angiographic analysis of 16,573 patients. exp Clin Cardiol. 2013; 18(2): 121-123.

5. Zhang LJ, Yang GF, Huang W, Zhou CS, Chen P, Lu GM. Incidence of anomalous origin of coronary artery in 1879 Chinese adults on dual-source CT angiography. Neth Heart J. 2010; 18: 466-470.

6. Andreini D, Mushtaq S, Pontone G, et al. Additional clinical role of 64-slice multidetector computed tomography in the evaluation of coronary artery variants and anomalies. Int J Cardiol. 2010; 145: 388-390.

7. Liu H, Zhu C, Guo Y, Zhang M, Li J. A rare case of complex anomalous origin of coronary arteries with severe atherosclerosis. Chin Med J (Engl). 2014; 127(24): 4297-4298.

8. Angelini P. Coronary artery anomalies: an entity in search of an identity. Circulation.2007; 115: 1296-1300.

9. Marler AT, Malik JA, Slim AM. Anomalous Left Main Coronary Artery: Case Series of Different Courses and Literature Review. Case Rep Vasc Med. 2013; 2013: 380952

10. Bartoli CR, Wead WB, Giridharan GA, Prabhu SD, Koenig SC, Dowling RD. Mechanism of myocardial ischemia with an anomalous left coronary artery from the right sinus of Valsalva. J Thorac Cardiovasc Surg. 2012; 144: 402-408.

11. Lee BY. Anomalous right coronary artery from the left coronary sinus with an interarterial course: is it really dangerous? Korean Circ J. 2009; 39: 175-179.

12. Angelini P. Novel Imaging of Coronary Artery Anomalies to Assess Their Prevalence, the Causes of Clinical Symptoms, and the Risk of Sudden Cardiac Death. Circ Cardiovasc Imaging. 2014; 7: 747-754.

13. Marchesini J, Campo G, Righi R, Benea G, Ferrari R . Coronary artery anomalies presenting with ST-segment elevation myocardial infarction. Clin Pract. 2011; 1(4): e107. 